\title{
Responding to the challenge of autism spectrum disorder in low-resource settings
}

Sir,

Autism spectrum disorder (ASD) has been categorized under the neurodevelopmental disorders, according to the Diagnostic and Statistical Manual of Mental Disorders-5 (DSM-5). ${ }^{[1,2]}$ The ASD comprises conditions such as autism, Asperger syndrome, pervasive developmental disorder not otherwise specified, and childhood disintegrative disorder. ${ }^{[1,2]}$ These disorders are usually identified by persistent deficits in social communication and interaction, along with a restricted, repetitive patterns of behavior, or actions. ${ }^{[1-3]}$ In contrast to the DSM-4 diagnostic criteria, the DSM- 5 does not consider communication as a distinct feature and has advocated for integrating social interaction and communication into single category alone ${ }^{[1,2]}$ A combination of many environmental and genetic factors have been identified which increases the risk of an individual for an ASD. ${ }^{[1]}$ The onset of most of the ASD is in the childhood phase within first 5 years of life while they tend to persist into the stages of adolescence and adulthood. ${ }^{[1]}$

The findings of the recent estimates suggest that on an average 1 in 160 children is a case of an ASD across the globe. ${ }^{[1]}$ However, the actual estimates are substantially higher as there is no surveillance mechanism to ensure universal reporting of each of these cases, especially in low- and middle-income nations. ${ }^{[4]}$ Further, the epidemiological studies performed in the last couple of decades have shown confirmatory evidence to suggest a rise in the prevalence of ASDs across the world. ${ }^{[4,5]}$ Different reasons such as an increase in the level of awareness, expansion of the diagnostic criteria, improvement in the diagnostic tools and reporting, have been identified for the eventual rise in the prevalence of ASDs. ${ }^{[1,5]}$

Moreover, the level of intellectual functioning of the patients is extremely variable, varying from mild to even profound impairment. ${ }^{[3]}$ In fact, individuals with ASD often simultaneously present with other mental illnesses such as seizure disorder, depression, or anxiety. ${ }^{[1]}$ Although some ASDs patients might be able to live independently, a large proportion of them has to face social deficits with impairment of skills/emotion, or severe disabilities necessitating lifelong care, and support services ${ }^{[3,6]}$ ASDs not only significantly restrict the ability of a person to perform routine activities and contribute to the society, but even remarkably reduce the educational and employment options for the affected person. ${ }^{[5,6]}$
Further, there is a great emotional and a financial burden on the family members to ensure the delivery of the desired supportive services to the people with ASDs. ${ }^{[1,7]}$ In addition, the ASD patients are extremely vulnerable to acquire noncommunicable diseases due to the presence of behavioral risk factors such as physical inactivity and poor dietary preferences. ${ }^{[1]}$ At the same time, people with ASDs have been repeatedly exposed to stigma, discrimination, and violation of human rights (viz. risk of violence, injury, and abuse). ${ }^{[5,7]}$ However, the extent of the problem becomes manifold wherever the access to care and supportive services is inadequate, especially in low-resource settings. ${ }^{[7]}$

From the management perspective, a targeted intervention during the early childhood and periodic monitoring remain the key interventions to facilitate the optimal development and well-being of people with ASDs. ${ }^{[1,5]}$ In addition, measures such as counseling family members about the different aspects of the disease, its prognosis, and types of services available; offering behavior therapy to negate the concerns of difficulty in communication and impairment of the social behavior; ensuring accessibility and availability of comprehensive package of services, including health promotion, rehabilitation and care services; formulating policies to enable coordination between different sectors to safeguard education or employment options of the affected persons; and supporting the above measures with broader measures to make the country's infrastructure more accessible, inclusive, and supportive..$^{[1,4-7]}$

In fact, the World Health Organization has acknowledged the scope of the problem and the impact it casts on the quality of life of people and the family members and thus has expressed its commitment time and again to support the nations to strengthen nation's capacities to respond to the varying needs of ASD patients. ${ }^{[1,5]}$ Further, measures have been taken to enhance the level of commitment by the policy makers, and to offer guidance in formulating evidence-based policies and action plans within the framework of mental health and disabilities. ${ }^{[1,5]}$

To conclude, caring for children diagnosed with ASD is one of the biggest challenges, especially in areas with limited access to support or health care services. It is high time that policy makers and other stakeholders should realize the significance of the problem, and thus work 
in collaboration to improve the reach and the range of services, especially in low-resource settings.

\section{Financial support and sponsorship \\ Nil.}

\section{Conflicts of interest}

There are no conflicts of interest.

\section{Saurabh RamBihariLal Shrivastava, Shruthi Krishnan',} Prateek Saurabh Shrivastava

Department of Community Medicine, Shri Sathya Sai Medical College and Research Institute and ${ }^{1}$ Shri Sathya Sai Medical College and Research Institute, Kancheepuram, Tamil Nadu, India

Address for correspondence: Dr. Saurabh RamBihariLal Shrivastava, Department of Community Medicine, Shri Sathya Sai Medical College and Research Institute, $3^{\text {rd }}$ Floor, Ammapettai Village, Thiruporur - Guduvancherry Main Road, Sembakkam Post, Kancheepuram - 603 108, Tamil Nadu, India. E-mail: drshrishri2008@gmail.com

\section{References}

1. World Health Organization. Autism Spectrum Disorders - Fact Sheet; 2016. Available from: http://www.who.int/mediacentre/factsheets/ autism-spectrum-disorders/en/. [Last accessed on 2016 Jan 13].

2. Diagnostic and Statistical Manual of Mental Disorders. DSM5 Autism Spectrum Disorder - Guidelines and Criteria Exemplars; 2013. Available from: https://www.depts.washington.edu/dbpeds/Screening\%20Tools/
DSM-5(ASD.Guidelines) Feb2013.pdf. [Last accessed on 2016 Mar 08].

3. Asada K, Tojo Y, Osanai H, Saito A, Hasegawa T, Kumagaya S. Reduced personal space in individuals with autism spectrum disorder. PLoS One 2016;11:e0146306.

4. Mandell D, Mandy W. Should all young children be screened for autism spectrum disorder? Autism 2015;19:895-6.

5. World Health Organization. Autism Spectrum Disorders and Other Developmental Disorders - From Raising Awareness to Building Capacity. Geneva: WHO Press; 2013. p. 1-26.

6. Volden J, Duku E, Shepherd C, Ba, Georgiades S, Bennett T, et al. Service utilization in a sample of preschool children with autism spectrum disorder: A Canadian snapshot. Paediatr Child Health 2015;20:e43-7.

7. Foley KR, Trollor J. Management of mental ill health in people with autism spectrum disorder. Aust Fam Physician 2015;44:784-90.

This is an open access article distributed under the terms of the Creative Commons Attribution-NonCommercial-ShareAlike 3.0 License, which allows others to remix, tweak, and build upon the work non-commercially, as long as the author is credited and the new creations are licensed under the identical terms.

\begin{tabular}{|l|l|}
\hline \multicolumn{2}{|c|}{ Access this article online } \\
\hline Quick Response Code: & Website: \\
\hline & www.ruralneuropractice.com \\
\hline & \\
\hline
\end{tabular}

How to cite this article: Shrivastava SR, Krishnan S, Shrivastava PS. Responding to the challenge of autism spectrum disorder in low-resource settings. J Neurosci Rural Pract 2016;7:472-3. 